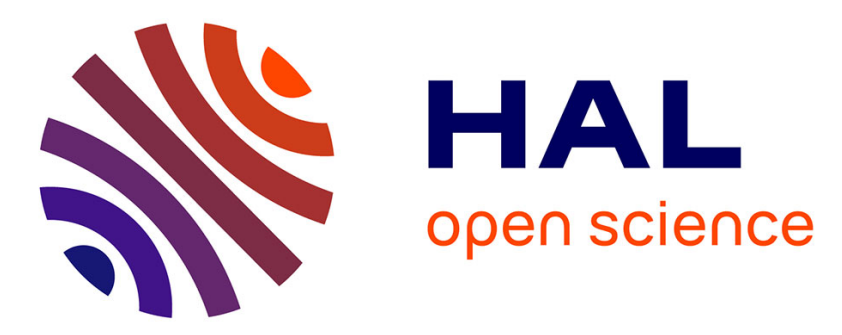

\title{
Gold-clay nanocomposite colloids with liquid-crystalline and plasmonic properties
}

Karin El Rifaii, Patrick Davidson, Laurent Michot, Cyrille Hamon

\section{To cite this version:}

Karin El Rifaii, Patrick Davidson, Laurent Michot, Cyrille Hamon. Gold-clay nanocomposite colloids with liquid-crystalline and plasmonic properties. Chemical Communications, 2021, 10.1039/D1CC03826E . hal-03368825

\section{HAL Id: hal-03368825 \\ https://hal.science/hal-03368825}

Submitted on 7 Oct 2021

HAL is a multi-disciplinary open access archive for the deposit and dissemination of scientific research documents, whether they are published or not. The documents may come from teaching and research institutions in France or abroad, or from public or private research centers.
L'archive ouverte pluridisciplinaire HAL, est destinée au dépôt et à la diffusion de documents scientifiques de niveau recherche, publiés ou non, émanant des établissements d'enseignement et de recherche français ou étrangers, des laboratoires publics ou privés. 
Received 00th January 20xx, Accepted 00th January 20xx

DOI: $10.1039 / x 0 \times x 00000 x$

\section{Gold-clay nanocomposite colloids with liquid-crystalline and plasmonic properties}

\author{
Karin El Rifaii, ${ }^{\text {*a }}$ Patrick Davidson, ${ }^{\mathrm{a}}$ Laurent Michot ${ }^{\mathrm{b}}$ and Cyrille Hamon*a
}

\begin{abstract}
Imparting liquid-crystal (LC) materials with the plasmonic properties of metal nanoparticles is actively pursued for applications. We achieved this goal by synthetizing gold nanoparticles onto clay nanosheets, leading to nematic nanocomposite suspensions. Optical observations and structural analysis show the growth of the gold nanoparticles without altering the LC properties of the nanosheets. These colloids display plasmonic structural colours and they can be aligned by an electric field, which is relevant for fundamental and materials chemistry of colloidal LC.
\end{abstract}

Anisotropic nanoparticles (NPs) can spontaneously self-assemble in colloidal suspension and display liquid-crystal (LC) organizations. The conditions to obtain colloidal LC in aqueous solvent are met for particles with high aspect ratio (e.g. rods, plates) and long-range electrostatic repulsive particle interactions. ${ }^{1,2}$ An emblematic example is the LC nematic phase of natural clay nanosheets. ${ }^{3,4}$ Interestingly, such LC organizations can often be observed at low volume fraction (e.g. $<1 \%$ ), resulting in typical distances between objects of hundreds of nanometers. For instance, aqueous suspensions of phosphatoantimonate, niobate, titanate, and zirconium hydrogenphosphate nanosheets display photonic properties that can be tuned by adjusting their volume fraction and thus their lamellar period from 150 to $600 \mathrm{~nm} \cdot{ }^{5-8}$ Similarly, aluminosilicate nanotubes form a hexagonal LC columnar phase at volume fractions as low as $0.2 \% .^{9}$ Detailed studies of colloidal LC have shown that the $\mathrm{pH}$, ionic strength, and the addition of chemicals could be used to control the interparticle distance. ${ }^{7,8,10}$ Moreover, colloidal LC readily respond to external fields, providing ways for dynamic control over the orientation of the particles..$^{11,12}$

Gold NPs can very efficiently absorb and scatter light because

\footnotetext{
a. Laboratoire de Physique des Solides, Université Paris-Saclay, CNRS, 91405 Orsay, France.

b. Laboratory of Physical Chemistry of Electrolytes and Interfacial Nanosystems (PHENIX), Sorbonne Université, CNRS, 75005 Paris, France.

Electronic Supplementary Information (ESI) available: Materials and methods and table of sample compositions, additional TEM images, sketch of the phase diagram, influence of beidellite concentration, size distributions of beidellite nanosheets and gold nanoparticles, additional SAXS and WAXS data of beidellite/gold suspensions, and influence of an a.c. electric field on a biphasic beidellite/gold suspension See DOI: $10.1039 / x 0 x x 00000 x$
}

of their ability to support coherent oscillations of electrons, the so-called surface plasmon resonance that is sensitive to the morphology of the NP and the polarization of the incident light. ${ }^{13}$ Combining colloidal LC with plasmonic NPs is promising toward reconfigurable metamaterial designs and dynamic colour displays driven by the facile response of the medium and the NPs to external stimuli. ${ }^{14-20}$ However, so far, advances in this direction have been mainly achieved by dispersing gold NPs in molecular LC hosts. Surprisingly, the successful combination of colloidal LC and gold NPs, in which the suspension would be both mesostructured and coloured, are quite scarce and mostly deal with nanowires rather than nanosheets. ${ }^{21-25}$ The strong sensitivity of colloidal LC to ionic strength and molecular additives presumably limits the chemistry that can be employed to obtain a plasmonic colloidal liquid crystal.

In this work, we achieved a successful marriage between the colloidal LC host and the gold NP dopant by synthetizing gold NPs at the surface of beidellite clay nanosheets, in-situ, forming a plasmonic clay-based nanocomposite colloid. Although beidellite LC suspensions are mesostructured, they are usually colourless because the typical distance between nanosheets is lower than $\approx 150 \mathrm{~nm}$. The gold NPs in the gold/beidellite nanocomposites that we prepared impart them with vivid blue or red plasmonic structural colours. In addition, we explored the influence of the concentrations of gold and beidellite on the stability of the colloidal nematic LC. Finally, we show that the nanocomposite colloids can be efficiently manipulated with electric fields.

In a typical synthesis (see ESI for experimental details), the proper amount of $\mathrm{HAuCl}_{4}$ was added to a beidellite aqueous suspension, followed by that of ascorbic acid (reducing agent), under vigorous stirring at room temperature. The reaction is instantaneous, as shown by the rapid colour change of the samples. In order to explore the influence of both the beidellite weight fraction and the gold precursor concentration, respectively labelled $C_{\text {beid }}$ and $C_{\text {gold }}$ hereafter, we prepared series of samples where only one of the two parameters was varied. Moreover, the concentration ratio of $\mathrm{HAuCl}_{4}$ to ascorbic acid, $\mathrm{C}_{\mathrm{aa}}$, was kept constant to $\mathrm{C}_{\mathrm{aa}} / \mathrm{C}_{\text {gold }}=10$ for all syntheses. 
Fig. 1a shows a series of samples, observed in natural light, with constant $\mathrm{C}_{\text {beid }}$ but with $\mathrm{C}_{\text {gold }}$ increasing from left to right, in a logarithmic way. The first sample is a control with no $\mathrm{HAuCl}_{4}$ and is completely colourless and homogeneous. By comparison, in the other vials, the growth of gold NPs induces the appearance of blue ( $C_{\text {gold }}=0.047$ and $0.16 \mathrm{mM}$ ) or red colours $\left(C_{\text {gold }}=0.47\right.$ and $\left.1.6 \mathrm{mM}\right)$. Transmission electron microscopy (TEM) observation confirmed the conjugation of gold NPs at the surface of the nanosheets, with a number of NPs per nanosheet varying from one to a few (Fig. S1-3, ESI). The number of gold NPs per nanosheet increased with Cgold
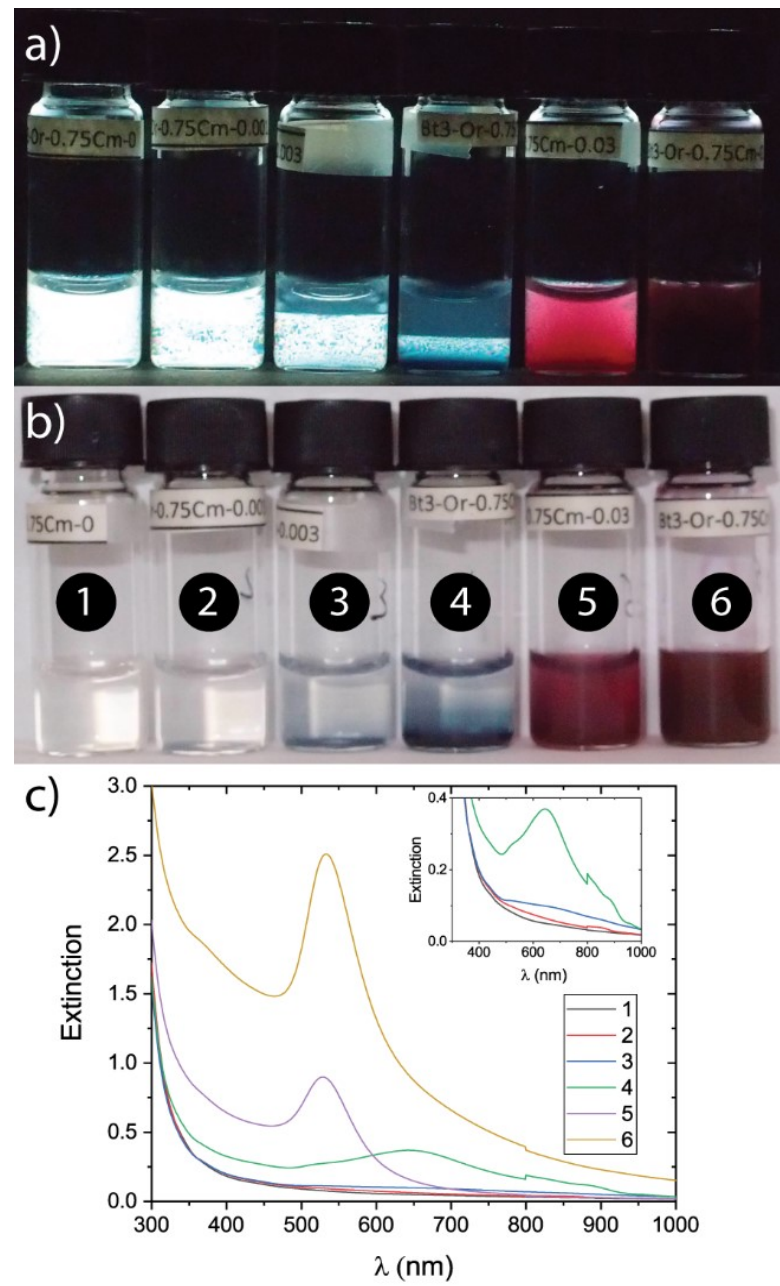

Fig. 1 Photographs of beidellite/gold samples observed in a) natural and b) polarized light, with $\mathrm{C}_{\text {beid }}=1.61 \mathrm{wt} \%$ and $\mathrm{C}_{\text {gold }}$ increasing from left to right : $C_{\text {gold }}=0,0.016,0.047,0.16,0.47$, and $1.6 \mathrm{mM}$; c) their respective UV-Vis absorption spectra.

but bare nanosheets were still frequently observed at all Cgold. This heterogeneity presumably induces differences in sedimentation, with heavier nanocomposite colloids localized at the bottom of the vials (smaller gravitational length), resulting in the vertical absorption gradient observed in Fig $1 \mathrm{~b}$. Such gradient is hardly visible in sample 6 , which could be due to its very strong light absorption and the fact that it is a gel. Overall, the growth of gold NPs in the beidellite suspensions does not compromise their colloidal stability. In contrast, gold NPs prepared without beidellite flocculated within $2 \mathrm{~h}$ after synthesis, except for the lowest $C_{\text {gold }}$ (Fig. S4). Nanocomposites were dialyzed against $\mathrm{MQ}$ water to remove molecular species from the dispersion and reduce the ionic strength. While samples 3-4 were biphasic before dialysis and 5-6 were gels, samples 3-6 turned monophasic (Fig. S6). This experiment shows that the salts used in the synthesis destabilize the LC properties of the host, which can be recovered upon dialysis. It also shows that the nanosheets stabilize the gold NPs since the system is stable without capping ligand (ascorbic acid). The stability of the gold NPs synthetized at the surface of beidellite is presumably due to the long-range electrostatic repulsions between the negatively-charged nanosheets. 25

Close inspection of the nanocomposite in TEM revealed beidellite nanosheets, visible in light-gray and gold NPs as black objects (Fig. 2, Fig. S1-3, ESI). The beidellite size distribution (Fig. S5, ESI) has a mean of $\approx 280 \mathrm{~nm}$ and a polydispersity of $50 \%$, values which remain very close to those of the initial beidellite batch. The gold NPs usually appear at the rim of the beidellite nanosheets (Fig S3, ESI), possibly due to an electrostatic attraction between oppositely-charged objects. The TEM images also revealed the formation of two different kinds of gold NPs. Nanostars were detected at moderate $\mathrm{C}_{\text {gold }}$ (samples 3 and 4, Fig. 2c) whereas compact spherical NPs were found at higher $C_{\text {gold }}$ (samples 5 and 6, Fig. 2b). The two different morphologies in samples 3-4 and 56 explain why the corresponding colours of the suspension are markedly different. The star-like particles are $\approx 21 \mathrm{~nm}$ in size whereas the spherical ones are $\approx 18 \mathrm{~nm}$ in diameter. (Fig. S5, ESI.)

The colour variation of the samples was studied more quantitatively by extinction spectroscopy (Fig. 1c). The pure beidellite suspension shows no absorption peak in the visible range, as expected, ${ }^{26}$ and sample 2 does not either, probably due to the high dilution of the gold species. In contrast, samples 3 and 4 display broad absorption peaks at $\approx 650 \mathrm{~nm}$, consistent with their blue colour, with peak intensity increasing with $\mathrm{C}_{\text {gold. }}$. Furthermore, samples 5 and 6 have broad and strong absorption peaks at $\approx 530 \mathrm{~nm}$, in line with their red colour, with peak intensity also increasing with $C_{\text {gold }}$. The dark coloration in sample 6 is due to the high $C_{\text {gold }}$.

The observation of the samples between crossed polarizers (Fig. 1b) shows that they remain birefringent after gold NP synthesis. More precisely, the pure beidellite suspension has a single birefringent phase which is nematic. ${ }^{4,27}$ Sample 2, which has the lowest $C_{\text {gold }}$, behaves in the same way. In contrast, samples 3 and 4 spontaneously demix in two phases: an isotropic phase at the top and the denser birefringent nematic at the bottom. Therefore, these samples belong to the biphasic domain in between the stability regions of the nematic and isotropic liquid in the phase diagram of the beidellite suspensions. In other words, although the nematic phase is not suppressed by the presence of gold NPs, it is destabilized with respect to the isotropic liquid phase (see a sketch of the phase diagram Fig. S7a, ESI). Very similar observations were made when beidellite clay suspensions were doped with either silica spheres or non-ionic flexible polymers. ${ }^{28,29}$ Moreover, as expected, the nematic phase 
vanished when the beidellite nanosheet concentration was decreased from 1.61 wt\% to 0.805 wt\% (Fig S8). ${ }^{4,27}$ This however did not impact the plasmonic properties of the nanocomposite colloid (Fig. S9). Upon further increase of $\mathrm{C}_{\text {gold }}$, the phase separation disappears, which is probably due to the fact that the samples become weak gels.
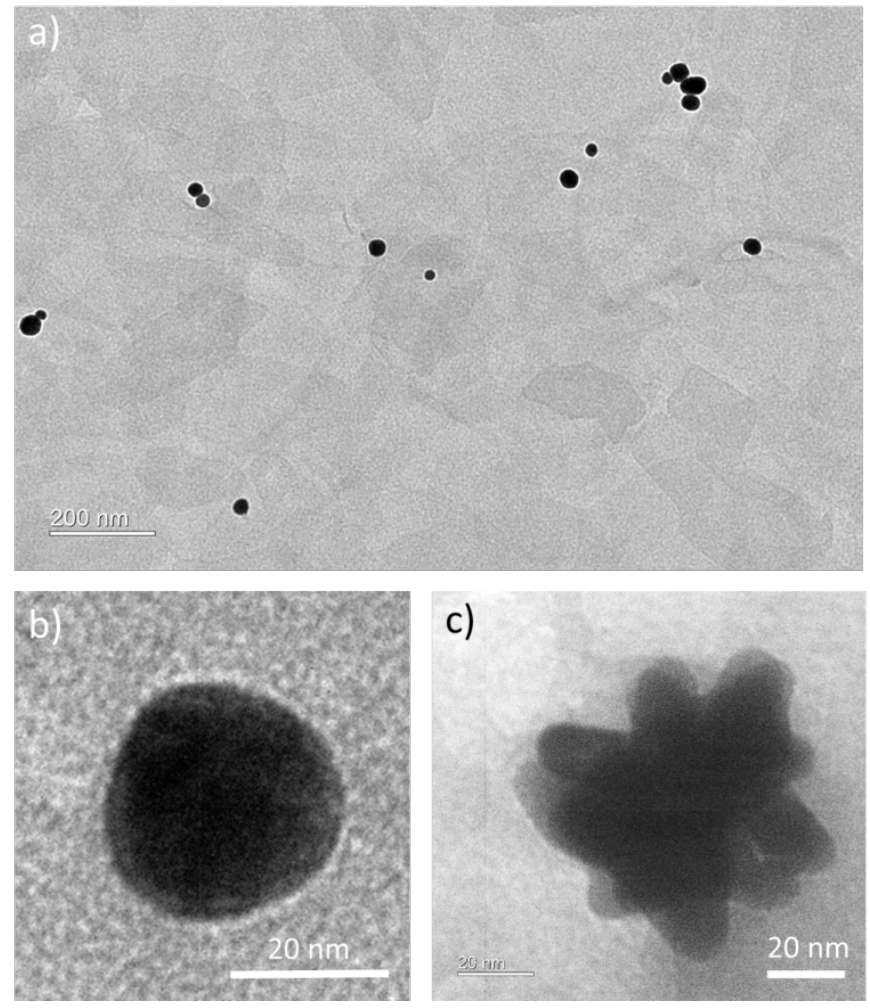

Fig. 2 TEM images showing gold NPs grown at the surface of beidellite nanosheets. (a) is a representative image of sample 5, showing gold NPs on beidellite nanosheets as well as bare nanosheets. $(b, c)$ respectively show magnified images of a NP and a nanostar observed in samples 5 and 4 respectively.

The small-angle X-ray scattering (SAXS) patterns of the birefringent phases of the samples only show broad scattering peaks typical of a liquid-like organization (Fig. 3a,b). Yet, these patterns are anisotropic. These two features together prove that the birefringent phases are actually nematic LC, as already reported for pure beidellite suspensions. ${ }^{4,27}$ The SAXS patterns are mostly dominated by the contribution of the beidellite nanosheets and the gold NPs must then be randomly distributed within the nematic phase. The azimuthallyaveraged scattered intensity I(q) (see Materials and Methods) of samples with and without addition of $\mathrm{HAuCl}_{4}$ are qualitatively very similar (Fig. $3 \mathrm{c}, \mathrm{d}$ ). The peak position shifts towards lower angle in the presence of gold NPs, which points to an increased separation ( $65 \mathrm{~nm}$ instead of $47 \mathrm{~nm}$ ) between clay nanosheets in the nematic phase. This might be due to the steric hindrance imposed by the gold NPs to the clay nanosheets, which could keep them further apart.

The SAXS signal of dilute suspensions has a $q^{-2}$ dependence typical of 2-dimensional objects (Fig. S10, ESI) while the WAXS signal shows the diffraction peak typical of the internal structure of the beidellite nanosheets (Fig. S11, ESI). Both of these features confirm that the growth of gold NPs does not alter the structure of the beidellite nanosheets.

Hereafter, we show that the electric-field alignment property of the colloidal suspensions is preserved in the presence of the
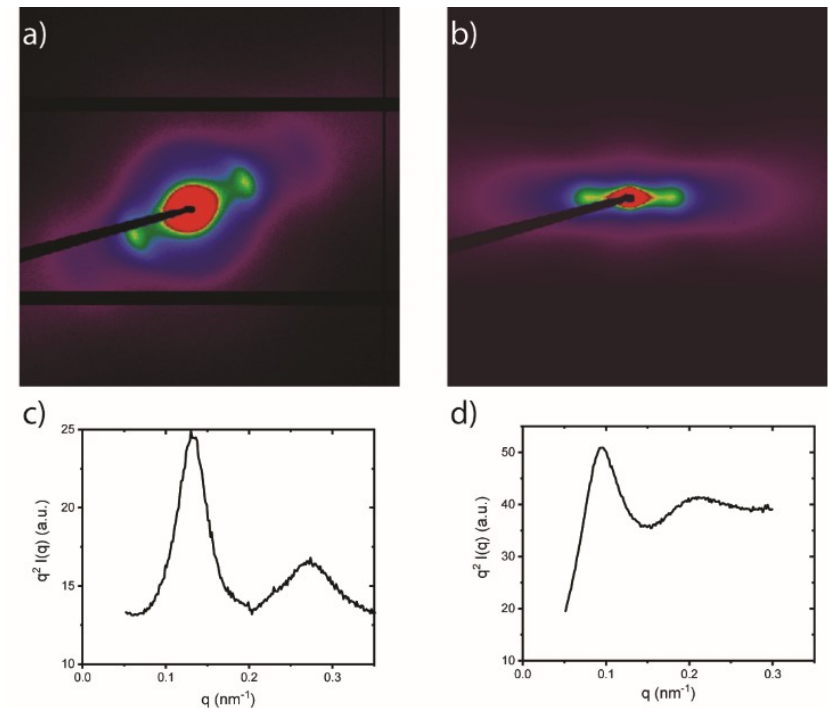

Fig. 3 SAXS patterns of nematic samples with constant $C_{\text {beid }}=1.61$ wt $\%$ a) with no $\mathrm{HAuCl}_{4}$ (sample 1 in Fig. 1); b) with $\mathrm{C}_{\text {gold }}=0.16 \mathrm{mM}$ (sample 4 in Fig. 1); (c,d) the corresponding curves of azimuthally-averaged scattered intensity in Kratky representation, $\mathrm{q}^{2} I(\mathrm{q})$ vs $\mathrm{q}$.

gold NPs. Fig. 4 shows the effect of an a.c. electric field on the nematic phase of a beidellite/gold suspension filled into a cylindrical glass capillary. In the absence of field (Fig. 4 a,b), there is no marked light-transmission variation when the capillary axis lies parallel or at $45^{\circ}$ from the polarizer direction. However, under field, the sample appears almost completely dark when the capillary is parallel to the polarizer direction (Fig. 4c) but much brighter when it lies at $45^{\circ}$ (Fig. 4d). This is proof of the good macroscopic alignment of the nematic phase. The alignment proceeds from the tendency of the clay nanosheets to rotate parallel to the electric field due to the polarization of their counter-ion clouds. ${ }^{30}$ This property is kept after the growth of the gold NPs.

The isotropic phase of beidellite/gold suspensions, at lower volume fraction than that of the nematic phase, also has similar field-alignment properties. Without field, it appears completely dark between crossed polarizers but it becomes very bright as soon as the field is applied (Fig. S12, ESI). This giant Kerr effect of the isotropic phase, well known for pristine beidellite nanosheets, ${ }^{30}$ is also kept when gold NPs are grown onto the nanosheets. In contrast with the nematic phase, it can be used to adjust the degree of nanosheet orientational order, from none to complete alignment, simply by tuning the intensity of the field.

In this work, we successfully combined the mesostructuration of a colloidal LC with the vivid colours imparted by gold NPS grown on beidellite nanosheets. Altogether, our optical, UVvis, and X-ray scattering experiments show that gold NPs of two different morphologies (stars and spheres) could be grown on clay nanosheets, preserving the nematic organization of the beidellite nanosheet suspensions. Moreover, both the isotropic liquid and the nematic phases kept their electric-field 
alignment properties. All these features make this original nanocomposite colloid system a good candidate for the fielddriven dynamic control of plasmonic structural colours.
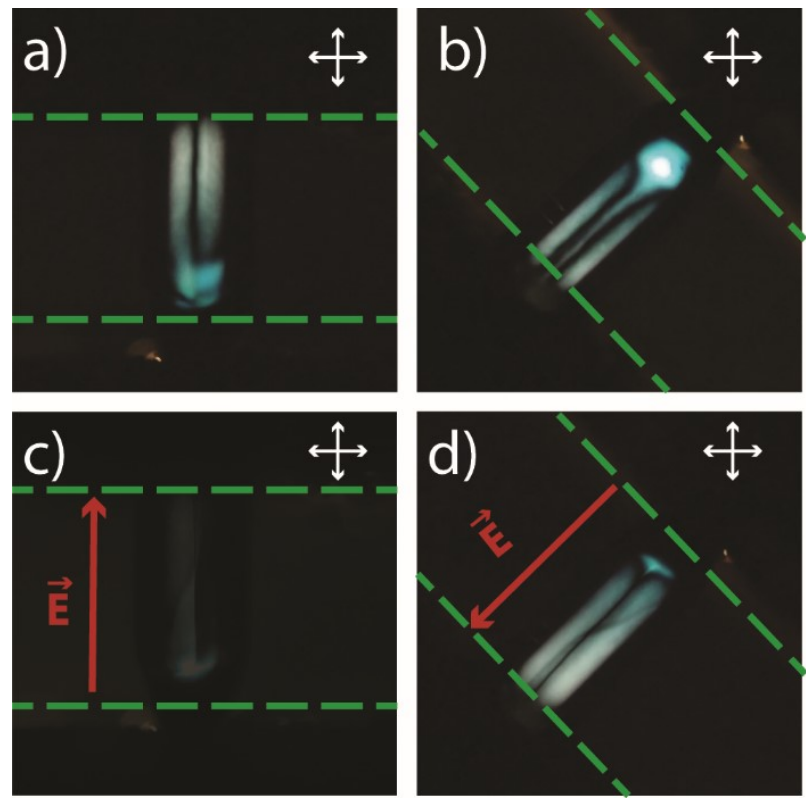

Fig. 4 Polarized-light microscopy images showing the alignment by an electric field of the nematic phase of a beidellite/gold suspension ( $C_{\text {beid }}=1.61 \mathrm{wt} \%, C_{\text {gold }}$ $=0.16 \mathrm{mM}$, sample 4 in Fig 1.) in a cylindrical capillary of $1 \mathrm{~mm}$ diameter. $(\mathrm{a}, \mathrm{b})$ Without field; (c,d) in an a.c. field (red arrow, $500 \mathrm{kHz}, 125 \mathrm{~V} \mathrm{rms}$ ). (Dashed lines show the borders of the electrodes. The white arrows show the polarizer and analyzer directions.)

\section{Conflicts of interest}

There are no conflicts to declare.

\section{Acknowledgements}

Claire Goldmann and Thomas Bizien are gratefully acknowledged for help with, respectively, the synthesis of the gold/beidellite nanocomposite colloids and the use of the Swing beamline. We acknowledge SOLEIL for provision of synchrotron radiation facilities (under the approved proposal \# 20191221). TEM observations were performed at the Imagerie-Gif core facility supported by l'Agence Nationale de la Recherche (ANR-11-EQPX-0029/Morphoscope; ANR-10-INBS04/FranceBiolmaging; ANR-11-IDEX-0003-02/Saclay Plant Sciences).

\section{Notes and references}

1 L. Onsager, Ann.NY Acad.Sci., 1949, 51, 627-659.

2 G. Vroege and H. Lekkerkerker, Rep. Prog. Phys., 1992, 55, 12411309.

3 L. J. Michot, I. Bihannic, S. Maddi, S. S. Funari, C. Baravian, P. Levitz and P. Davidson, Proc. Natl. Acad. Sci. U. S. A., 2006, 103, 16101-16104.

4 E. Paineau, A. M. Philippe, K. Antonova, I. Bihannic, P. Davidson, I. Dozov, J. C. P. Gabriel, M. Imperor-Clerc, P. Levitz, F. Meneau and L. J. Michot, Liq. Cryst. Rev., 2013, 1, 110-126.
5 J. C. P. Gabriel, F. Camerel, B. J. Lemaire, H. Desvaux, P. Davidson and P. Batail, Nature, 2001, 413, 504-508.

6 N. Miyamoto and T. Nakato, Isr. J. Chem., 2012, 52, 881-894.

7 K. Sano, Y. S. Kim, Y. Ishida, Y. Ebina, T. Sasaki, T. Hikima and T. Aida, Nat. Commun., 2016, 7, 12559.

8 M. Zeng, D. King, D. Huang, C. Do, L. Wang, M. Chen, S. Lei, P. Lin, Y. Chen and Z. Cheng, Proc. Natl. Acad. Sci. U. S. A., 2019, 116, 18322-18327.

9 E. Paineau, M.-E. M. Krapf, M.-S. Amara, N. V. Matskova, I. Dozov, S. Rouziere, A. Thill, P. Launois and P. Davidson, Nat. Commun., 2016, 7, 10271.

10 K. Szendrei, P. Ganter, O. Sanchez-Sobrado, R. Eger, A. Kuhn and B. V. Lotsch, Adv. Mater., 2015, 27, 6341-+.

11 S. Fraden, G. Maret, D. Caspar and R. Meyer, Phys. Rev. Lett., 1989, 63, 2068-2071.

12 D. Bordel, J.-L. Putaux and L. Heux, Langmuir, 2006, 22, 48994901.

13 J. Olson, S. Dominguez-Medina, A. Hoggard, L.-Y. Wang, W.-S. Chang and S. Link, Chem. Soc. Rev., 2015, 44, 40-57.

14 O. Stamatoiu, J. Mirzaei, X. Feng and T. Hegmann, in Liquid Crystals: Materials Design and Self-Assembly, ed. C. Tschierske, Springer-Verlag Berlin, Berlin, 2012, vol. 318, pp. 331-393.

15 F. Neubrech, X. Duan and N. Liu, Sci. Adv., 2020, 6, eabc2709.

16 Q. Liu, Y. Cui, D. Gardner, X. Li, S. He and I. I. Smalyukh, Nano Lett., 2010, 10, 1347-1353.

17 Q. Liu, Y. Yuan and I. I. Smalyukh, Nano Lett., 2014, 14, 40714077.

18 S. Khatua, P. Manna, W.-S. Chang, A. Tcherniak, E. Friedlander, E. R. Zubarev and S. Link, J. Phys. Chem. C, 2010, 114, 7251-7257.

19 M. Wojcik, W. Lewandowski, J. Matraszek, J. Mieczkowski, J. Borysiuk, D. Pociecha and E. Gorecka, Angew. Chem.-Int. Edit., 2009, 48, 5167-5169.

20 W. Lewandowski, M. Fruhnert, J. Mieczkowski, C. Rockstuhl and E. Gorecka, Nat. Commun., 2015, 6, 6590.

21 Q. Liu, M. G. Campbell, J. S. Evans and I. I. Smalyukh, Advanced Materials, 2014, 26, 7178-7184.

22 J. Van Rie, G. Gonzalez-Rubio, S. Kumar, C. Schutz, J. Kohlbrecher, M. Vanroelen, T. Van Gerven, O. Deschaume, C. Bartic, L. M. Liz-Marzan, G. Salazar-Alvarez and W. Thielemans, Chem. Commun., 2020, 56, 13001-13004.

23 T. Nakato and T. Kasai, Materials Letters, 2011, 65, 3402-3404.

24 E. H. Hill, N. Claes, S. Bals and L. M. Liz-Marzan, Chem. Mat., 2016, 28, 5131-5139.

25 L. Liz-Marzan and A. Philipse, J. Phys. Chem., 1995, 99, 1512015128.

26 N. Yamaguchi, S. Anraku, E. Paineau, C. R. Safinya, P. Davidson, L. J. Michot and N. Miyamoto, Sci Rep, 2018, 8, 4367.

27 E. Paineau, K. Antonova, C. Baravian, I. Bihannic, P. Davidson, I. Dozov, M. Imperor-Clerc, P. Levitz, A. Madsen, F. Meneau and L. J. Michot, J. Phys. Chem. B, 2009, 113, 15858-15869.

28 J. Landman, E. Paineau, P. Davidson, I. Bihannic, L. J. Michot, A.M. Philippe, A. V. Petukhov and H. N. W. Lekkerkerker, J. Phys. Chem. B, 2014, 118, 4913-4919.

29 K. El Rifaii, H. H. Wensink, T. Bizien, J.-C. P. Gabriel, L. Michot and P. Davidson, Langmuir, 2020, 36, 12563-12571.

30 I. Dozov, E. Paineau, P. Davidson, K. Antonova, C. Baravian, I. Bihannic and L. J. Michot, J. Phys. Chem. B, 2011, 115, 7751-7765. 